\title{
Ignacio Ellacuría: un \\ humanismo latinoamericano del siglo XX
}

\author{
Adriana María Arpini \\ Instituto de Ciencias Humanas, Sociales \\ y Ambientales (INCIHUSA), CONICET \\ Facultad de Filosofía y Letras, \\ Universidad Nacional de Cuyo, Argentina
}

Resumen: Sostenemos que Ignacio Ellacuría es un humanista, pero no en el sentido del humanismo clásico, renacentista o ilustrado, sino en el sentido disruptivo y crítico que identifica al humanismo latinoamericano del siglo XX. Tras una breve caracterización de los criterios que permiten pensar la alternativa de un humanismo emergente de nuestra América, nos detenemos en el análisis de algunos textos ellacurianos a fin de constatar cómo se modulan en ellos los rasgos propios de nuestro humanismo en el siglo XX.

Palabras clave: Filosofía, Antropología, Humanismo, Ignacio Ellacuría, Crítica Intrahistórica, Ideología.

Abstract We maintain that Ignacio Ellacuria is a humanist, although not in the fashion of Classic, Renaissance or Enlightenment cultures, but in the disruptive and critical way that identifies the $X X^{\text {th }}$ Century Latin American Humanism. After assessing the criteria for the characterization of an emerging humanism in our America, we analyze some of Ellacuria's writings seeking the specific characteristics of our humanism in the $X X^{\text {th }}$ Century.

Key words: Philosophy, Anthropology, Humanism, Ignacio Ellacuría, Intrahistorical Critique, Ideology.

Con el término "Humanismo" se designa al primero y más amplio de los movimientos intelectuales que caracterizan el pensamiento en la etapa del Renacimiento. Desde el siglo XIV, la expresión studia 
humanitatis comenzó a utilizarse para señalar un conjunto orgánico de disciplinas que se ocupan del hombre en lo que tiene de más específico, elevado y creador (gramática, retórica, poesía, historia y filosofía moral) (Colomer, 1997). Su cultivo estuvo indisolublemente unido al acrecentamiento de la dignidad humana en el marco del humanismo clásico.

Con la Ilustración se acentuó la fe en la razón que, todavía para Kant, debía realizarse en sus dimensiones teórica, práctica y como capacidad de juzgar (estética, ética y política). La fe en la razón alentó la confianza en el progreso material y humano. En este contexto, tuvo sentido pensar la humanidad como fin, tanto de la ética como de la política y la historia (Kant), incluso fue posible pensar la realización de la libertad en la historia universal (Hegel).

Sin embargo, a lo largo de la modernidad, la relación entre progreso y desarrollo científico tecnológico acabó por comprimir las posibilidades de la razón, reduciéndola a su dimensión puramente instrumental y escindida de la preocupación por el cultivo y acrecentamiento de lo propiamente humano, lo que conllevó la instrumentalización de los saberes y las prácticas.

Ya en el siglo XIX europeo, los filósofos de la sospecha llamaron la atención acerca de lo que se percibía como resultados negativos de la modernidad: la reducción del valor de los seres humanos y de la vida misma a mero valor de cambio, es decir a mera mercancía (Marx); la transformación de la voluntad de poder como afirmación de la vida, a voluntad de dominio y de opresión de la vida (Nietzsche); el malestar de una cultura que en su afán de proteger la civilización acaba por producir represión y barbarie (Freud).

La puesta en crisis de los humanismos durante el siglo XX como consecuencia de la instrumentalización de la razón y de las catástrofes humanas acaecidas -guerras mundiales, campos de concentración, armas de destrucción masivapusieron en evidencia que los rasgos característicos del humanismo clasicista - por una parte la exaltación de lo humano que por su dignidad merece ser cultivado, por otra parte, la convicción de que tal cultivo se logra por medio de las letras clásicas en virtud de su carácter ejemplar- no son inescindibles. Antes bien, como ha sugerido José Luis Aranguren, es posible la afirmación de la dignidad humana como tarea ilimitada en el marco de una concepción de la historia abierta a lo inédito, a la diversidad, al reconocimiento de la alteridad (Aranguren y otros, 1957).

Aunque el sentido actual del humanismo no coincida exactamente con el que tuvo en su origen renacentista, es posible reconocer ciertas 
marcas comunes a los humanistas de todos los tiempos. Entre ellas, el esfuerzo por responder ciertas preguntas: ¿cómo son los hombres?, ¿cómo deben ser en cuanto a afán de saber, a su dignidad y belleza?, ¿cuál es el modo de convivencia social $u$ organización política que privilegia el ejercicio de la autonomía?

La primera pregunta remite a una cuestión antropológica, pues supone un estudio acerca de la subjetividad, es decir, una reflexión sobre las condiciones y las prácticas, materiales y simbólicas, a través de las cuales o en oposición a las cuales emergen formas concretas, singulares y/o colectivas, de afirmación del/los sujeto/s.

La segunda pregunta implica un análisis de los modos de entablarse las relaciones del hombre consigo mismo, con los otros, con el mundo cultural y natural. Es decir, un estudio de las formas de autoafirmación, de conocimiento y de reconocimiento de la diversidad, con especial referencia a las relaciones de subalternidad y de injusticia social, cultural y ecológica. Esto es una cuestión que se inscribe en las dimensiones epistemológica, ética y estética.

La tercera pregunta apunta a la dimensión política, entendida como una investigación acerca de las estrategias de organización y de transformación de la gramática social, cultural y ecológica, según criterios que favorezcan el reconocimiento de lo diverso y la afirmación más plena de los sujetos en orden a su realización y al ejercicio de la libertad.

Sin embargo, aun cuando se acentúe el impulso renovador del humanismo en lo que se refiere a cuestiones antropológicas, epistemológicas, éticas, estéticas y políticas, tales transformaciones de la vida y la cultura se mantienen dentro de los marcos de la modernidad occidental. Un desafío mayor se presenta cuando se trata de pensar las formas de organizar la vida y la sociedad de culturas que son radicalmente diferentes, sin caer en el exotismo, es decir en la mera curiosidad o admiración de lo otro, sólo porque es extraño.

Cabe plantear el problema en términos de una "ecología de los saberes" en el marco de lo que Boaventura de Sousa Santos ha llamado "pensamiento posabismal" (De Sousa Santos, 2010). Ello es posible si se admite la premisa de que el pensamiento occidental moderno es abismal. Esto es una forma de pensamiento que consiste en un sistema de distinciones que trazan un límite -un abismo- más allá del cual lo existente desaparece como realidad, o bien es producido como no existente, no comprensible, es excluido de las formas de saber y de la gramática socio-cultural. Lo característico del pensamiento 
abismal es la imposibilidad de la co-presencia contemporánea de los dos lados de la línea. Razón por la cual, esta forma de pensamiento, llevada al rango de universalmente válida, produce déficit de reconocimiento, subalternación, formas múltiples de sometimiento. Desde esta perspectiva y en relación con nuestra América es oportuno preguntar por las características diferenciales de un pensamiento humanista crítico latinoamericano.

Nos interesa puntualizar el ejercicio de la sospecha y de la crítica llevado adelante desde la perspectiva de nuestra América. Ello nos da la posibilidad de reparar en la necesidad de otros criterios para orientar los saberes y las prácticas en condiciones sociales, históricas y geográficas diferentes. Tal es el caso de los escritos filosóficos de Ignacio Ellacuría, los cuales se inscriben en una línea de producción ensayística cultivada por nuestros filósofos y pensadores desde el siglo XIX. En dichos ensayos se reflexiona a partir de los procesos concretos de nuestra realidad histórica marcada por la condición colonial y por relaciones de dependencia. Tales ensayos pueden ser leídos como ejercicios de sospecha y propuestas de humanismos emergentes latinoamericanos, entre ellos se cuenta el emblemático texto "Nuestra América" de José Martí, donde podemos leer:

\section{El libro importado ha sido vencido en América por el hombre natural. Los hombres naturales han vencido a los letrados artifi- ciales. [...] No hay batalla entre la civilización y la barbarie, sino entre la falsa erudición y la naturaleza [...].}

Viene el hombre natural, indignado y fuerte, y derriba la justicia acumulada en los libros, porque no se la administra de acuerdo con las necesidades patentes del país. Conocer es resolver. Conocer el país y gobernarlo conforme al conocimiento es liberarlo de tiranías (Martí, 2005). ${ }^{1}$

El texto martiano muestra cómo opera el pensamiento abismal en todas las dimensiones: epistemológica, antropológica, ética y política. De un lado, el "libro importado", los "letrados artificiales", la "falsa erudición", la "justicia acumulada en los libros", todos ellos desconocen lo que está del otro lado, esto es, las "necesidades patentes del país" demandadas por el "hombre natural", así tal desconocimiento o imposibilidad de co-presencia es causa de las "tiranías". Pero no se trata para Martí de reproducir dicotomías o de invertirlas sin más, se trata más bien de producir una reflexión performativa a partir del conocimiento y valoración de lo propio. Saber de sí, de las propias necesidades, sin desconocer 
las producciones del conocimiento "universal", poniéndolo a funcionar para la satisfacción de las propias demandas sociales y culturales a la altura de los tiempos. En otras palabras, organizar las capacidades existentes para posibilitar la liberación de las tiranías. En este sentido, para Martí, "gobernante, en un pueblo nuevo, quiere decir creador" (Martí, 2005, p. 33).

La sospecha de Martí y su propuesta obligan a introducir al menos las siguientes cuestiones que contribuyen a esclarecer criterios epistemológicos con los cuales sería posible pensar la alternativa de un humanismo crítico nuestroamericano, o mejor, de nuestros humanismos:

a. Explorar la capacidad cognitiva de lo imaginario - no exclusivamente de la razón, pero tampoco en lugar de ésta- como condición de posibilidad y potencia creadora de lo humano.

b. Problematizar las bases teóricas de una epistemología que, imbuida de la idea de progreso, privilegia la pauta temporal y explica las diferencias en el orden de las sucesiones. Problematizarla, decimos, desde una mirada que permita la ampliación del presente, privilegiando un criterio espacial, que hace posible apreciar diversidad de contenidos y de puntos de vista existentes en un mismo momento.

c. Considerar la posibilidad y conveniencia de un criterio intrahistórico de crítica de la realidad. Sobre este aspecto en particular vale remitirse la propuesta humanista de Ignacio Ellacuría. Como se explica más adelante, para el filósofo salvadoreño, ${ }^{2}$ la crítica social más penetrante no es aquella que se hace en función de la sociedad ideal ni de una pretérita, ambas ideales o idealizadas, sino aquella que toma en cuenta las capacidades y recursos existentes en el presente, y se pregunta si podría sacarse de ellos un mejor rendimiento para la realización de la condición humana; es decir que problematiza una sociedad determinada a partir de sus propias posibilidades de ser una sociedad mejor.

d. Una adecuada caracterización del humanismo latinoamericano del siglo XX exige una consideración de sus propias manifestaciones discursivas, ya sea a través de proclamas o declaraciones públicas, ya sea por medio de teorizaciones realizadas por nuestros intelectuales, la mayoría de las 
veces en forma de ensayos. Muchos de estos son escritos de envergadura filosófica, cuya originalidad reside en la invención o redefinición de categorías analítica y proyectivas, en tensa relación, con las que se busca dar cuenta de situaciones problemáticas $y / o$ conflictivas, al mismo tiempo que se imaginan posibles transformaciones de la realidad.

e. De acuerdo con Arturo Roig (Roig, 1984), entre las características del pensamiento humanista latinoamericano a partir de sus propias manifestaciones pueden señalarse: plantear la búsqueda de un modelo histórico abierto; constituirse como ideología de un grupo o sector social subalterno emergente; presentarse como afirmación de la propia subjetividad personal, social y/o colectiva; acompañar modos de auto $y$ heterorreconocimiento; $y$ organizarse como un modo sui generis de ejercicio dialéctico (Arpini, 2015, p. 31-44).

Proponemos el análisis de algunos textos producidos por Ignacio Ellacuría a fin de constatar la presencia de estas características y delinear el perfil de un humanismo emergente nuestro-americano.

\section{Acerca del quehacer filosófico}

En un escrito breve, destinado a quienes están obligados en el bachillerato o en la universidad a tomar cursos de filosofía sin ningún interés vocacional por la disciplina, y muchas veces sin sentir siquiera curiosidad por ella, Ellacuría intenta despejar la pregunta por el sentido de la filosofía y de su enseñanza. No se trata de un asunto de mera erudición o "barniz cultural", pues en tal caso no podría hablarse de filosofía, tampoco se trata de un saber en el mismo sentido que el conocimiento científico.

Para el filósofo salvadoreño, la pregunta por el quehacer filosófico de los hombres en condiciones socio-históricas concretas sólo puede ser entendida a cabalidad si se la invierte: ¿a qué se ha debido que los hombres se hayan visto forzados a filosofar? El análisis del ejemplo de Sócrates ofrece una pista. Sócrates vivió como ciudadano de Atenas en el siglo $V$ antes de Cristo y fue filósofo porque fue ciudadano, se interesó por los problemas de la ciudad. A diferencia de quienes le precedieron, consideraba que el verdadero problema radicaba en el conocimiento que el hombre debe tener de sí mismo, de ahí su famoso dicho: conócete a ti mismo. 
Quería saber -dice Ellacuría-, pero lo que buscaba en ese saber era hacerse a sí mismo y hacer a la ciudad. Su saber es, por tanto, un saber humano y un saber político [...] su objetivo era la recta humanización y la recta politización (Ellacuría, 2001, p. 117).

El suyo era un saber crítico. No se contentaba con saber lo que las cosas son, sino que se interesaba por que llegaran a ser verdaderas, bellas y justas. Para eso era necesario, además de talento, disponer de una técnica, de un método que permitiera definir y conceptualizar, inducir y dialectizar. Su propósito era evitar la ideologización, la falta de crítica y la insuficiencia metódica. Por estas razones, Ellacuría piensa que Sócrates "recompuso la trayectoria de la filosofía”.

Pero el filosofar se diferencia también del saber del científico, pues éste busca la certeza basada en lo experimentalmente verificable y el funcionamiento de las cosas expresado en leyes, pero cuanto más consigue saber por esta vía, más preguntas se abren y más cuestiones quedan sin resolver.

¿Qué es, entonces, lo que el filósofo busca saber? En primer lugar, se pregunta, como el científico, el porqué de las cosas, pero lo entiende de un modo peculiar, no desea establecer conexiones entre antecedente y consecuente, sino que quiere conocer la estructura misma de la realidad, entendida en su unidad total y última. En segundo lugar, advierte que no puede decir lo que es la realidad sin hacer referencia a lo que es conocer, ni puede decir lo que es conocer sin hacer referencia a la realidad. Así surge el hombre como conexión ineludible entre conocer y realidad. El hombre es la pieza clave de la filosofía y de filosofar, atormentado siempre por la pregunta:

\section{[...] qué es realmente la realidad y en ella qué soy realmente como hombre [...] Es aquí donde aparece la historia como lugar de plenificación y de revelación de la realidad: el hombre socialmente considerado y haciendo historia es el lugar de la manifestación de la realidad (Ellacuría, 2001, p. 123).}

Así, pues, la pregunta por el por llevar adelante una investigahombre es inescindible de la ción sobre la filosofía de la realidad pregunta por la realidad; uno y otra histórica, que da título a su obra encuentran su realización en la póstuma (a la que nos referimos más historia. De ahí el interés ellacuriano adelante). 
El tercer campo del saber filosófico es interrogar por el sentido de la realidad, esto es la pregunta acerca del para qué de las cosas. El sentido de las cosas hace siempre referencia a la vida humana. En última instancia, es una pregunta por el sentido de la vida humana, que involucra tanto la vida personal como la vida social, política e histórica.
El saber filosófico es así un ingente esfuerzo de la humanidad por aclararse a sí misma qué es saber, qué es realidad y cuál es el sentido de la vida humana. Es un esfuerzo estrictamente racional, un esfuerzo sin el cual a la postre le faltaría a la huma- nidad racionalidad y criticidad (Ellacuría, 2001, pp. 123 -124).

Ahora bien, es posible que la filosofía haya servido de justificación a un orden imperante, sobre todo cuando el filósofo se instala en un saber que no es tal, sino más bien una "ignorancia interesada". Entonces, se plantea el problema del quehacer de la filosofía respecto a las ideologías, Ellacuría lo explica del siguiente modo: todo saber tiene un contenido inmediato - lo que se sabe- y tiene, además, relación con una determinada situación: la del individuo que lo construye y la del momento socio-histórico en que aparece. El elemento ideologizador se refiere no tanto al contenido, sino más bien a la relación con la situación o las acciones que el saber puede desencadenar. En este sentido, la práctica de la filosofía como ejercicio crítico por parte de Ellacuría entronca, por un lado, con manifestaciones del humanismo clásico - $v$. gr. el de Pico della Mirándola- en tanto búsqueda no sólo de la paz interior mediante el conocimiento de la filosofía - natural y moral- y el ejercicio de la dialéctica, sino también en tanto se propone intervenir en la discusión pública de las principales controversias filosóficas a fin de producir un reordenamiento de los saberes que redunde en el esclarecimiento de ideas acerca del hombre y de la sociedad transmitidas y aceptadas sin cuestionamientos. Por otro lado, entronca con la práctica humanista latinoamericana $-v$. gr. la de José Martí- en la medida que la búsqueda del saber filosófico es un modo de auto y heterorreconocimiento crítico y contextualizado -criticar para transformar-. En ambas tradiciones de humanismo crítico se trata de "saber para desideologizar".

Cabe entonces, siguiendo al filósofo salvadoreño, preguntar: ¿es la filosofía principio de ideologización o de desideologización? Si bien todo pensamiento está situado y condicionado, ello no implica que esté predeterminado, antes bien, mantiene relativa autonomía. Sin esta autonomía no serían posibles ni la denuncia ni la liberación de la ideologización, las cuales se ejercen 
desde el pensamiento mismo; esto exige una consideración crítica de todos los condicionamientos. Tanto la ideologización como la crítica son posibles porque el pensamiento no está totalmente determinado; si así fuera, todos pensaríamos lo mismo, cosa que de hecho sucede con quienes en realidad no piensan.
Es por eso que los regímenes autoritarios ponen obstáculos al pensar, coartan la autonomía del pensamiento. La filosofía pretende desarrollar a fondo la autonomía, liberando al pensamiento de toda imposición para llevar adelante su tarea de racionalidad crítica.

Los mecanismos de la crítica son para el autor "la duda y la negación", pues "disminuyen la velocidad de la acción, rompen el carácter monolítico de la organización, dan paso a desahogos individualistas, [...] muestran la autonomía del pensamiento, su capacidad de convertir la determinación en indeterminación, la necesidad en libertad" (Ellacuría, 2001, p. 127).

En efecto, la filosofía busca sobrepasar cualquier determinación para abarcar la totalidad. En ello se encuentra latente un riesgo de ideologización, cuando se intenta sustituir la realidad por una representación o construcción de la misma o bien cuando se ignora una parte de la realidad. Al contrario, el filósofo que ejercita la crítica aspira a explicar lo real como instrumento de aproximación, como recorridos posibles, como medios de realización y creación de alternativas.

Así pues, la filosofía sirve para saber -saber de sí y de la propia realidad-y para desideologizar. El modo en que Sócrates la ejerció constituye un ejemplo de ello, que trasciende el interés de un beneficio personal. Todos necesitamos de la filosofía, la sociedad la necesita, como saber crítico y creador, capaz de poner en tela de juicio las creencias que perpetúan un orden injusto y violento. Se impone, entonces la pregunta ¿cómo filosofar? Ellacuría señala que el auténtico pensar filosófico surge del examen de la propia situación histórica, lo cual no implica un aislacionismo que impida reconocer e incluso asimilar lo que otros han pensado en situaciones históricas diferentes. Tal conocimiento no se busca como erudición o moda, sino como herramientas para saber cómo es la realidad en que se está. De ahí la importancia de enseñar a pensar, de suscitar el espíritu crítico frente a la realidad y a cualquier sistema que intente explicarla, de fomentar la creatividad para el análisis, la comprensión y el hallazgo de respuestas, de formación técnica para entrar en contacto con los grandes pensadores y ser capaces de producir pensamiento propio. 
Filosofar - dice Ellacuría- no es la transmisión y aprendizaje de una serie de contenidos más o menos entendidos, sino la puesta en marcha de la propia capacidad de pensamiento filosófico. [...] La filosofía [...] es así un elemento indispensable en la liberación integral de nuestros pueblos. Cuando estos pueblos cuenten con la posibilidad real de pensar por sí mismos en todos los órdenes del pensamiento, es que ya van camino de la libertad y de la posesión plena de sí mismos. He ahí el para qué de la filosofía (Ellacuría, 2001, p. 130 - 131).

\section{Capacitación y posibilitación: dialéctica singular y ejercicio de la crítica intrahistórica}

Ellacuría encuentra que las reflexiones de su maestro, Xavier Zubiri, acerca de la estructura dinámica de la realidad le permiten iluminar y definir el horizonte teórico y práctico de la filosofía y su objeto en el sentido de la liberación. Los análisis zubirianos en Sobre la esencia buscaban explicar "lo que la realidad es actualmente", lo que ella es "de suyo". En La estructura dinámica de la realidad, Zubiri avanza sobre el problema del devenir, esto es, lo que la realidad "puede dar de sí". Ambos son complementarios, de modo que las realidades son estructuras que "de-suyo-dan-de-si" (Zubiri, 1989). ${ }^{3}$

Por su parte, Ellacuría acentúa que el dinamismo de la realidad concluye en la historia, donde se hacen presentes todos los demás dinamismos de lo real, que a su vez son afectados por la historia; lo cual significa que la realidad es constitutivamente histórica. La trascendentalidad de la realidad es "el mundo histórico"y si la filosofía pretende dar cuenta de lo que última y totalmente es la realidad, entonces la historia se convierte en el verdadero objeto de la filosofía. Ahora bien, para el filósofo salvadoreño no se trata de pensar el dinamismo histórico en general, sino desde una situación histórica concreta. Específicamente desde la sufriente realidad salvadoreña -y latinoamericana- en las décadas de los 70 y 80 , y se trata, además, de pensar críticamente esa realidad desde la perspectiva de quienes padecen injusticias.

Lo propio de la realidad intramundana es su carácter dinámico, Ellacuría sostiene que este dinamismo no es unívocamente dialéctico. Una adecuada interpretación de la dialéctica permite ver que la negación no es sólo aniquiladora de su contrario, sino anuladora y superadora. Consecuentemente, la realidad es un proceso de realización en el cual se van dando cada vez formas más altas de realidad que retienen y superan a las anteriores. No se trata de una deducción lógica, sino real: "El mundo de las cosas 
reales no sólo está abierto a nuevas tativa, esto es estricta novedad, no cosas reales, sino a nuevas formas mero despliegue o explicitación de de realidad en cuanto tal" (Ellacuría, lo mismo. Dice Ellacuría: 1991, p. 37). Su novedad es cuali-

Hay un estricto dar-de-sí-más de lo que actualmente es y esto no sólo cuantitativamente - no en el sentido de un aumento cuantitativo de la materia inicial-, sino en el sentido de darse más cosas reales diferenciadas, sino, sobre todo, cualitativamente, esto es, mediante la aparición de nuevas formas de realidad. [...] no podemos decir lo que es la realidad hasta que ella misma no dé-todo-de-sí y no podemos decir lo que es la realidad superior deduciéndola de las formas inferiores de la realidad de la cual proviene (Ellacuría, 1991, p. 37-38).

El fragmento citado pertenece a su libro Filosofía de la realidad histórica. José Manuel Romero Cuevas afirma que en ese libro, Ellacuría asume "un posicionamiento humanista comprometido con la realización humana" basado en una "filosofía radicalmente histórica", a fin de "clarificar la actividad crítica como algo que recibe su base normativa del propio proceso histórico de realización de capacidades y posibilidades humanas" (Romero Cuevas, 2009, pp. 129-144). ${ }^{4}$ Si bien Ellacuría entiende que los problemas deben ser planteados en relación con una humanidad que en el actual decurso histórico ha devenido en "una"; ello no implica adoptar una perspectiva teórica puramente formal o abstracta, desde la cual se eluden los conflictos y se disimulen las relaciones de subalternación. Al contrario, para nuestro autor, el quehacer filosófico está siempre situado en un entramado histórico conflictivo que constituye un desafío para el pensamiento crítico, pues no puede eludir una toma de posición frente a una realidad histórica que reproduce estructuras injustas. Si la historia es el verdadero objeto de la filosofía, entonces su tarea consiste en elaborar categorías críticas que permitan no sólo comprender el dinamismo de la realidad, sino que, impulsadas por un interés ético-político, posibiliten la transformación de dicha realidad.

En efecto, Ellacuría explica que "la historia no flota sobre sí misma" (Ellacuría, 1991, p. 388). El enfrentamiento de la realidad histórica desde la perspectiva de la especie plantea el problema de la transmisión de formas somáticas y de formas de vida con características singulares: el hombre, además de recibir por transmisión genética determinadas estructuras psico-orgánicas, recibe también, aunque no genéticamente, 
determinadas formas de estar en la realidad. La instalación en la vida implica transmisión y entrega -se trata, en términos de Zubiri, de una "transmisión tradente"-.

\begin{abstract}
Toda vida humana - dice Ellacuría - comienza así montada sobre un modo de estar en la realidad que le ha sido entregado. Sólo se puede entregar algo a una esencia abierta, la cual por ser sentientemente abierta, necesita que junto con la transmisión genética, se le entregue una forma de estar en la realidad [...] La tradición de formas de estar en la realidad es el mecanismo por antonomasia de lo histórico; es, más aún, un ingrediente formal de la historia, pero no es toda la historia (Ellacuría, 1991, p. 391). ${ }^{6}$
\end{abstract}

La historia articula transmisión y tradición, pero su razón formal está en la tradición, lo cual permite distinguir entre lo histórico y lo natural en lo referente a las sociedades humanas y a la vida de cada uno; al mismo tiempo que permite reconocer que la naturaleza no es completamente ajena a la realidad integral de la historia aunque no la agote. Hay otros aspectos de la historia que atañen a su carácter formal, uno fundamental es la "actualización de posibilidades". Veámoslo.
En la transmisión tradente se entrega una forma de estar en la realidad, basada en una doble necesidad: por parte de quien entrega, por el carácter filético y social de la transmisión; por parte de quien la recibe, por la necesidad de apoyarse en una forma concreta de estar en la realidad para empezar a buscar su propia forma. Es decir que lo entregado posibilita el estar en la realidad pero no determina a quien lo recibe a permanecer en esa forma, sino que ante lo entregado tiene el "poder" de optar.

Lo que formalmente se transmite en la tradición de formas de estar en la realidad son, ante todo, posibilidades. [...] [En el sentido de] aquello que posibilita. $Y$ posibilitar consiste formalmente en dar un poder sin dar una necesidad fija y unidireccional de realización de ese poder. Aquí, el poder es optar (Ellacuría, 1991, p. 411).

En este punto se pone en juego la libertad humana y la libertad histórica, porque las posibilidades sólo pueden realizarse por un acto de opción y de apropiación, cuya ejecución no es un hecho más, sino un "suceso", por ello puede afirmarse que la historia es "el suceso de los 
modos de estar en la realidad" (Ellacuría, 1991, p. 420).

El sistema de posibilidades que, en determinado momento histórico, están al alcance y han sido apropiados por sujetos individuales o por un cuerpo social son "capacidades históricas" cualitativamente nuevas. Tales capacidades se dan cuando es posible hacer cosas distintas en virtud del acceso a un ámbito de posibilidades comunicadas por tradición y actualizadas por apropiación, de modo que lo propiamente histórico aparece como "transmisión tradente" en un doble proceso mutuamente realimentado de "actualización de posibilidades" o posibilitación y de "creación de capacidades” o capacitación.

El proceso de capacitación abarca las dimensiones cognitivas y tecnológicas, pero también las sociales y morales, de modo que la capacidad reconoce el valor de cada ser humano, de cada grupo como tal. Pero dicho reconocimiento no se realiza en ausencia de conflictos, al contrario, es resultado de una tensión, de una lucha. Se trata de un proceso por el cual se adquiere la capacidad de apreciar los rasgos y cualidades propias y de los otros como valiosas, es decir que se asume el carácter intersubjetivo del proceso de capacitación y posibilitación, el cual se cumple en relación con el mundo -naturaleza, cultura- y con los otros -otras personas, otras culturas, otra generación, otro grupo social, otro género y otra clase-.

La adquisición de nuevas capacidades abre nuevas posibilidades en la dimensión práctica, cognitiva y moral. La cuestión de qué posibilidades son de hecho realizadas no es un problema solamente técnico, sino político, pues las posibilidades históricamente iluminadas pueden resultar restringidas al sometimiento de las condiciones de reproducción del sistema social, frustrando la gratificación y satisfacción de las necesidades de numerosos grupos sociales.

La dialéctica entre capacitación y posibilitación está organizada de acuerdo con un principio dinámico de no identidad, es decir de no correspondencia entre forma y contenido. A diferencia de Hegel, Ellacuría otorga prioridad al contenido. Éste confiere dinamicidad, pues su maduración es lo que torna inviable la forma que había tenido hasta entonces, y acaba convirtiendo a la forma existente en un obstáculo que debe ser removido. La relación entre forma y contenido no es ontológica, sino históricamente iluminada desde una perspectiva político-moral específica. De esta manera, la no-identidad puede ser tematizada desde una mirada crítica de lo existente, orientada a su transformación. La concepción de lo histórico como proceso de capacitación y posibilitación aparece como algo contingente, frágil, sometido a 
retrocesos y pérdidas, pero también como acontecer de la novedad históricamente posible. Por tanto, es un proceso tematizable, susceptible de ser criticado y transformado (Ellacuría, 1991, pp. 420, 439 ss).

En otras palabras, si en un momento histórico determinado, la ciencia y la técnica han desarrollado una cierta capacidad, $v$. gr. la de satisfacer las necesidades alimentarias de la población mundial -momento de afirmación dialéctica o tesis-, y no obstante existen poblaciones o sectores sociales subalimentados -negación dialéctica o antítesis-, entonces es necesario tomar una decisión ético-política que abra paso a la negación de la negación, es decir, una decisión que contribuya a eliminar las causas que impiden a esa realidad histórica dar todo de sí. En casos como estos, la realidad histórica evidencia una contradicción entre el proceso de capacitación y el de posibilitación. Plantea una tensión que deja ver la contingencia del proceso histórico, dice Ellacuría:

\begin{abstract}
[...] el dinamismo de la historia, el dinamismo creador de la posibilitación y de la capacitación [...] toma una forma especial: se hace praxis histórica. La praxis hay que entenderla en el conjunto del dinamismo de la realidad. [...] La dinamicidad de la realidad es tan trascendental como la realidad misma, con lo que toda concepción quieta o quietadora no es sólo una huida de la realidad, sino una reacción contra ella, una verdadera contra-realización. [...] Sólo el hombre "realiza" formalmente aquello que hace y realiza realizándose y es en este ámbito de la realización formal donde ha de situarse la praxis. De ahí que no todo hacer sea una praxis, sino tan sólo aquel hacer que es un hacer real de realidad; un hacer, por otra parte, que va más allá del puro hacer natural, porque la historia, siendo siempre hecho, es siempre más que hecho, y este "más" es el novum, que el hombre añade a la naturaleza, desde ella, pero sobre ella. Si se quiere hablar de transformación, la transformación que definiría la praxis sería la intromisión de la actividad humana, como creación de capacidades y apropiación de posibilidades, en el curso dinámico de la historia (Ellacuría, 1991, pp. 470-471).
\end{abstract}

\section{En síntesis}

Los escritos de Ignacio Ellacuría que hemos considerado ponen de manifiesto una forma de ejercicio de la filosofía en la que es posible reconocer elementos que caracterizan el pensamiento humanista de todos los tiempos, en la medida que contribuye a la realización de lo 
específicamente humano, pero además, es posible identificar elementos diferenciales del humanismo emergente de nuestra América en el siglo XX, en tanto la afirmación de la dignidad humana involucra una reflexión contextualizada socio-históricamente con marcado sentido performativo, a partir de la propia situación subalternación y sometimiento.

La inversión de la cuestión por el sentido de la filosofía que lleva a preguntar ¿por qué los hombres se han visto obligados a filosofar?, nos coloca frente a una forma del quehacer reflexionante que parte de condiciones socio-históricas concretas y busca conocer la estructura de la realidad, apelando a un cierto método crítico que permita saber de sí y de la realidad, evitando la ideologización -que muchas veces es "ignorancia interesada", justificación de lo dado y pérdida del sentido crítico-. Así pues, el ejercicio de la filosofía trasciende la práctica profesional y se realiza como examen - en tanto ejercicio de una racionalidad crítica- de la propia realidad histórica en vistas a la liberación integral del hombre y de los pueblos. A diferencia del sentido negativo de la ideologización, es posible rastrear en los escritos ellacurianos una forma afirmativa de ideología, como capacidad de ampliar las posibilidades del presente, imaginando alternativas diferentes, mediante una racionalidad crítica no tutelada.
El sustento teórico de dicha práctica de la filosofía se encuentra en el examen de la realidad histórica. En efecto, dado que la realidad es constitutivamente histórica, entonces la historia es el verdadero objeto de la filosofía. El análisis del dinamismo histórico es un desafío para un ejercicio crítico de la razón, pues no se trata de apelar a deducciones lógicas o a la constatación de procesos naturales con un sentido prefijado, al contrario, se trata de un dinamismo abierto a la novedad, que exige categorías que lo expliquen y que problematicen el presente a partir de sus propias posibilidades de transformación. Ellacuría apela a categorías zubirianas tales como "transmisión tradente", "actualización de posibilidades" y "creación de capacidades", pero radicaliza su carácter intersubjetivo, crítico e intrahistórico. Así pone al descubierto una tensión dialéctica específicamente histórica, entre capacitación y posibilitación, que no se resuelve por apelación a una lógica regida por el principio de no contradicción, pues admite la contingencia, la posibilidad de tomar direcciones diferentes, la apertura a la novedad histórica, es decir, la intromisión de la actividad humana libre en la historia: un "suceso", que no es más que una praxis histórica de transformación.

En definitiva, se verifica en el pensamiento del filósofo salvadoreño la apelación a un modelo 
histórico abierto, la denuncia de ideologización como ausencia de crítica frente a la afirmación de la propia subjetividad -individual y social- a través de un ejercicio crítico de una filosofía que no rehúye las contradicciones de la realidad, sino que busca transformarla mediante una praxis histórica liberadora.

\section{Referencias bibliográficas}

- Aranguren, J. L ; Grousset, R. y otros. (1957). Hacia un nuevo humanismo. Madrid, España: Guadarrama.

- Arpini, A. M. (2015). Diversidad y reconocimiento: para una revisión del Humanismo. Pico della Mirándola y Bartolomé de las Casas. En Arpini, A. M. (Coord.), El humanismo, los humanismos. Ideas y prácticas revisadas desde nuestra América (p. 31-44). Mendoza, Argentina: EDIUNC (Editorial de la Universidad Nacional de Cuyo).

- Colomer, E. (1997). Movimientos de renovación. Humanismo y Renacimiento. Madrid, España: Akal.

- De Sousa Santos, B. (2010). Para descolonizar occidente: más allá del pensamiento abismal. Buenos Aires, Argentina, Consejo Latinoamericano de Ciencias Sociales: Prometeo.

- Ellacuría, I. (2001). Escritos filosóficos III. San Salvador: UCA Editores.

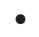
.(1991). Filosofía de la realidad histórica. Madrid: Trotta-Fundación Xavier Zubiri.

- Fernández, David, S. J. (2006). Ignacio Ellacuría: vida, pensamiento e impacto en la universidad jesuita de hoy. México, Universidad Iteramericana-Cátedra Ignacio Ellacuría.

- Hegel, G. W. F. (1986). Lecciones sobre la Filosofía de la Historia Universal (Traducción del Alemán por José Gaos). Madrid, España: Alianza Editorial.

- Martí, J. (2005). Nuestra América. República Bolivariana de Venezuela: Fundación Biblioteca Ayacucho (31-39). Recuperado de www.bibliotecayacucho.info/.../dscript.php?fname=Nuestra_America

- Mora Galiana, J. (marzo de 1999). Ignacio Ellacuría. Perfil biográfico, pensamiento y praxis histórica. Universidad de Huelva, España. Recuperado de http://www.ensayistas.org/filosofos/spain/ellacuria/introd.htm

- _ (Junio de 2001). El objeto de la filosofía: la realidad histórica en cuanto tal. Universidad de Huelva, España. Recuperado de http://www. ensayistas.org/filosofos/spain/ellacuria/critica/mora5.htm 
- Ribera, R. (2000). La civilización de la pobreza: la radicalidad del último Ellacuría. Recuperado de http://www.ensayistas.org/filosofos/spain/ellacuria/critica/ribera.htm

- Roig,A.A. (1984). Momentos y corrientes del pensamiento humanista en el Ecuador. En El Humanismo ecuatoriano en la segunda mitad del siglo XVIII Tomo I. Quito, Ecuador: Banco Central del Ecuador.

- Romero Cuevas, J. M. (2009). Humanismo, historia y crítica en Ignacio Ellacuría. En Rüsen, J. y Kozlarek, O. (Coords). Humanismo en la era de la globalización. Desafíos y perspectivas (129-144). Buenos Aires, Argentina: Biblos.

- Rüsen, J. y Kozlarek, O. (Coords). (2009). Humanismo en la era de la globalización. Desafíos y perspectivas. Buenos Aires, Argentina: Biblos.

- Samour, H. (1993). Historia praxis y liberación en el pensamiento de Ignacio Ellacuría. Ponencia presentada en el Primer Congreso Internacional Xavier Zubiri. Recuperado de http://www.ensayistas.org/filosofos/spain/ ellacuria/critica/samour.htm . (2014). La filosofía de la liberación. En Fornet Betancourt, R. y Beorlegui, C. Filosofía latinoamericana (pp. 2013-246). Granada, España: Editorial Comares.

- Zubiri, X. (1982). La dimensión histórica del ser humano. En Siete ensayos de Antropología filosófica (pp. 117-174), (Edición de Germán Marquínez Argote). Bogotá, Colombia: USTA. . (1989). Estructura dinámica de la realidad. Madrid, España: Alianza Editorial-Fundación Xavier Zubiri. - (2008) Sobre la esencia. Madrid, España: Alianza EditorialFundación Xavier Zubiri.

\section{Notas}

1 "Nuestra América", de José Martí fue publicado en la Revista llustrada de Nueva York, Estados Unidos, el 10 de enero de 1891, y en El Partido Liberal, México, el 30 de enero de 1891) (Martí, 2005).

2 Aunque Ignacio Ellacuría nació en 3 Portugalete, Provincia de Vizcaya, España, el 9 de noviembre de 1930, lo consideramos -adoptamos- como filósofo salvadoreño porque en este lugar del mundo, donde murió en 1989, realizó lo más importante de sus obras y de sus prácticas, a través de las cuales intentó comprender y transformar la sufriente realidad histórica del pueblo.

"La historia -dice Zubiri- está, a mi modo de ver, montada sobre el concepto de posibilidad [...] Y por esto la historia es una actualización de posibilidades. 
El pasado va legando un sistema de posibilidades que constituyen el presente sobre el cual el hombre monta sus proyectos y su vida individual, y hasta estructuras sociales para el futuro, pero es justamente esto: un alumbramiento y una obturación de posibilidades" (Zubiri, 1989, p. 269).

4 El autor sostiene que en el pensamiento de Ellacuría se produce un desplazamiento 7 respecto al de Zubiri que lo coloca en la dirección de lo que Horkheimer denominó "teoría crítica", de tal modo que sus categorías filosóficas son elaboradas desde un posicionamiento ético político previo que impulsa y da vida a la labor teórica.

5 "Entrega se llama parádosis, traditio, tradición. El proceso histórico es concretamente tradición" (Zubiri, 1982, pp. 117-174).

6 El resaltado es nuestro.

En este sentido, Ellacuría historiza la expresión de Xavier Zubiri: «lo que la realidad "da de sí"» (Ellacuría, 1991, p. $446 \mathrm{ss})$. 